\title{
A prospective multicenter study on the evaluation of antimicrobial resistance and molecular epidemiology of multidrug-resistant Acinetobacter baumannii infections in intensive care units with clinical and environmental features
}

\author{
Baris Boral ${ }^{1}$, Özlem Unaldi², Alper Ergin ${ }^{3}$, Riza Durmaz ${ }^{2,4}$, Özgen Köseoğlu Eser ${ }^{1 *}$ \\ and the Acinetobacter Study Group
}

\begin{abstract}
Background: Multidrug-resistant (MDR) Acinetobacter baumannii infections are considered as emerging nosocomial infections particularly in patients hospitalized in intensive care units (ICUs). Therefore, reliable detection of MDR strains is crucial for management of treatment but also for epidemiological data collections. The purpose of this study was to compare antimicrobial resistance and the clonal distribution of MDR clinical and environmental A. baumannii isolates obtained from the ICUs of 10 different hospitals from five geographical regions of Turkey in the context of the demographic and clinical characteristics of the patients.
\end{abstract}

Methods: A multicenter-prospective study was conducted in 10 medical centers of Turkey over a 6 month period. A total of 164 clinical and 12 environmental MDR A. baumannii isolates were included in the study. Antimicrobial susceptibility testing was performed for amikacin (AN), ampicillin-sulbactam (SAM), ceftazidime (CAZ), ciprofloxacin (CIP), imipenem (IMP) and colistin (COL) by microdilution method and by antibiotic gradient test for tigecycline (TIG). Pulsed-field gel electrophoresis (PFGE) was performed to determine the clonal relationship between the isolates. The detection of the resistance genes, bla $a_{\mathrm{OXA}-23}, b / a_{\mathrm{OXA}-24}, b / a_{\mathrm{OXA}-51}, b / a_{\mathrm{OXA}-58,}, b / a_{\mathrm{IMP},}, b / a_{\mathrm{NDM}}, b / a_{\mathrm{KPC}}, b / a_{\mathrm{OXA}-48}$ and bla $a_{\mathrm{PER}-1}$ was carried out using the PCR method.

Results: The mortality rate of the 164 patients was 58.5\%. The risk factors for mortality included diabetes mellitus, liv1er failure, the use of chemotherapy and previous use of quinolones. Antimicrobial resistance rates for AN, SAM, CAZ, CIP, IMP, COL and TIG were 91.8\%, 99.4\%, 99.4\%, 100\%, 99.4\%, 1.2\% and 1.7\% respectively. Colistin showed the highest susceptibility rate. Four isolates did not grow on the culture and were excluded from the analyses. Of 172 isolates, $166(96.5 \%)$ carried bla $a_{\mathrm{OXA}-23,}, 5(2.9 \%) b / a_{\mathrm{OXA}-58}$ and one isolate (0.6\%) was positive for both genes. The frequency of bla $a_{\text {PER-1 }}$ was found to be $2.9 \%$. None of the isolates had bla $a_{I M P}, b / a_{\mathrm{KPC}}, b / a_{\mathrm{NDM}}$ and bla $a_{\mathrm{OXA}-48}$ genes. PFGE analysis showed 88 pulsotypes. Fifteen isolates were clonally unrelated. One hundred fifty-seven (91.2\%) of the isolates were involved in 14 different clusters.

\footnotetext{
*Correspondence: ozgen.eser@hacettepe.edu.tr

1 Department of Medical Microbiology, Hacettepe University Faculty

of Medicine, Ankara, Turkey

Full list of author information is available at the end of the article
} 
Conclusions: Colistin is still the most effective antibiotic for A. baumannii infections. The gene bla $a_{\mathrm{OXA}-23}$ has become the most prevalent carbapenemase in Turkey. The distribution of invasive A. baumannii isolates from different regions of Turkey is not diverse so, infection control measures at medical centers should be revised to decrease the MDR A. baumannii infections across the country. The results of this study are expected to provide an important baseline to assess the future prophylactic and therapeutic options.

Keywords: Acinetobacter baumannii, Risk factors, Antimicrobial resistance genes, Polymerase chain reaction, Pulsed field gel electrophoresis, Clonal relatedness

\section{Introduction}

Invasive infections due to Acinetobacter baumannii are among the leading nosocomial infections in patients hospitalized in intensive care unit (ICU) [1]. The increasing number of these infections and the emergence of multidrug-resistant (MDR) strains make A. baumannii a troublesome pathogen especially in a hospital environment [1]. A. baumannii accounts for almost $90 \%$ of all reported Acinetobacter infections including ventilator-associated pneumonia, bacteremia, meningitis, peritonitis, urinary tract infections and wound infections [2].

Hospital-acquired pneumonia represents the most common clinical manifestation of $A$. baumannii infections. A. baumannii is also a common cause of bloodstream infections in ICUs [3]. The most common sources of these infections are the patients having lower respiratory tract infections and intravascular devices [4]. Risk factors include immunosuppression, ventilator- associated respiratory failure, previous antibiotic therapy, colonization with $A$. baumannii and invasive procedures [5].

Initial effective treatment is key to increasing the survival rate in bacterial infectious diseases however providing such treatment is a major clinical challenge due to the high rate of antibiotic resistance. For instance, increasing carbapenem resistance in $A$. baumannii infections is a serious threat for causing a rise in healthcare costs and worsening clinical outcome. The main mechanism of carbapenem resistance in $A$. baumannii is hydrolysis of carbapenems with metallo-beta-lactamases and/or class D beta lactamases. Although metallo-beta-lactamases (VIM, IMP, SIM) have been reported especially in Asia and Western Europe, class D beta-lactamases (OXA23, OXA-24 or -40 , OXA-51, OXA-58, and OXA-143) have been identified in the United States, Latin America, Europe, Asia and many other parts of the world [6, 7]. Studies of the class D beta-lactamases show that especially the $b l a_{\mathrm{OXA}-23}$ gene can be easily spread via transposons and conjugative plasmids [8]. The successful evolution of transposons bearing the bla $a_{\mathrm{OXA}-23}$ resistance gene has an important role in spreading the resistant bacteria worldwide [8].

Various genotyping methods such as ribotyping, pulsed-field gel electrophoresis (PFGE), multilocus sequence typing (MLST), single locus sequence typing (SLST), and analysis of restriction fragment length polymorphism (RFLP) can be used to understand transmission dynamics of MDR A. baumannii. The PFGE technique is known as the gold standard for genotyping of A. baumannii strains [9].

Epidemiological studies on the clinical and molecular characteristics of A. baumannii strains might help to determine infection control strategies for different centers. The purpose of this study was to evaluate antimicrobial drug resistance mechanisms and the clonal distribution of clinical and environmental MDR A. baumannii isolates from ICUs in five geographical regions of Turkey and to compare these with the demographic characteristics of the patients.

\section{Methods}

Study design

A prospective multicenter study was conducted from 10 different medical centers located in five different geographical regions (Aegean, Central and Eastern Anatolia, Marmara, Mediterranean) of Turkey in 2012. All patients who were admitted to the ICUs of medical centers with the diagnosis of invasive A. baumannii infections were included in the study. The study was reviewed and approved by the Non-Interventional Clinical Research Ethics Committee of Hacettepe University, Ankara, Turkey.

\section{Patient characteristics and risk factors}

The characteristics and risk factors of 164 patients with clinical and microbiological diagnosis of A. baumannii were analyzed. Data were collected prospectively in a standardized case report form. The following data were recorded in all centers: age, gender, occupation, immunosuppression, underlying diseases, previous hospitalization, duration of stay in the unit, invasive procedures or surgery within 30 days before the diagnosis, prior antibiotic treatment and outcome of treatment. Invasive procedures included central and urinary catheterization, mechanical ventilation, nasogastric tube placement, and orotracheal intubation. 


\section{Sample collection and identification of the isolates}

A total of 164 clinical and 12 environmental A. baumannii isolates were included in the study. The participating centers were Hacettepe University Hospitals (HACET) (Center 1), Gazi University Hospital (GAZI) (Center 2), Ankara Education and Research Hospital (AH) (Center 3), Ankara Ataturk Education and Research Hospital (AEH) (Center 4), Kayseri Education and Research Hospital (KEAH) (Center 5), Canakkale Onsekiz Mart University Hospital (Center 6), Dr. Lutfu Kirdar Education and Research Hospital (Center 7), Ataturk University, Research Hospital (Center 8), Ege University Hospital (Center 9) and Mersin University Hospital (Center 10) (Fig. 1). All the patients had monomicrobial infection with MDR A. baumannii. Clinical isolates were obtained from patients hospitalized in medicine and surgery ICUs, with samples taken from blood (89\%) and other sterile body sites [cerebrospinal fluid (CSF), bronchoalveolar lavage fluid (BAL), pleural fluid, tissue and catheter]. Environmental isolates were taken from table surfaces, sinks, taps and pumps from the ICUs in all centers.

All isolates were identified by automated systems [either the Vitek 2 system (bioMérieux, Marcy-l'Étoile, France) or Phoenix system (Becton-Dickinson, Franklin Lakes, NJ)] and they were confirmed at Hacettepe University Faculty of Medicine, Department of Medical Microbiology by conventional methods and also by molecular methods for confirming the existence of the $b l a_{\text {OXA-51 }}$ gene. All the confirmed isolates were kept at $-80^{\circ} \mathrm{C}$ during the data collection period.

\section{Antimicrobial susceptibility testing}

Antimicrobial susceptibility tests were performed for six antimicrobials; ampicillin-sulbactam (SAM), amikacin (AN), ceftazidime (CAZ), ciprofloxacin (CIP), imipenem (IMP) and colistin (COL) by using the broth microdilution method according to Clinical Laboratory Standards Institute (CLSI) guidelines [10]. Pseudomonas aeruginosa ATCC 27853 strain was used as a reference control in all antibiotic susceptibility testings except for sulbactam-ampicillin. Escherichia coli ATCC 35218 was used as a reference control for this antibiotic. In addition, the minimal inhibitory concentration (MIC) value for tigecycline (TIG) was determined by antibiotic gradient strips, Etest (bioMérieux, France). Interpretation break points for TIG of $\leq 1 \mathrm{mg} / \mathrm{L}$ were considered as susceptible, and $\geq 4 \mathrm{mg} / \mathrm{L}$ as resistant and MIC values against tigecycline were evaluated using FDA-approved breakpoints provided in the package insert [11].

\section{Detection of antibiotic resistance genes}

Two multiplex PCR protocols were carried out for the detection of resistance genes; one for $b l a_{\text {OXA-23 }}, b l a_{\text {OXA-2 }}$

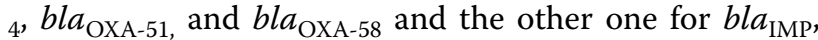
$b l a_{\mathrm{NDM}}, b l a_{\mathrm{KPC}}, b l a_{\mathrm{OXA}-48}$ in all 172 isolates $[12,13]$. The existence of the $b l a_{\mathrm{PER}-1}$ gene was also determined by using a protocol which was described by Weldhagen et al. [14]. Each PCR reaction $(25 \mu \mathrm{L})$ contained $12.5 \mu \mathrm{L}$ of Taq PCR master mix (New England Biolabs, Beverly, MA), $5.5 \mu \mathrm{L}$ sterile-RNase free water, $0.5 \mu \mathrm{L}$ of each primer $(100 \mu \mathrm{M}$, final concentration $2 \mu \mathrm{M})$ and $2 \mu \mathrm{L}$ of DNA template. Amplified products were visualized on $2 \%$ agarose gel.

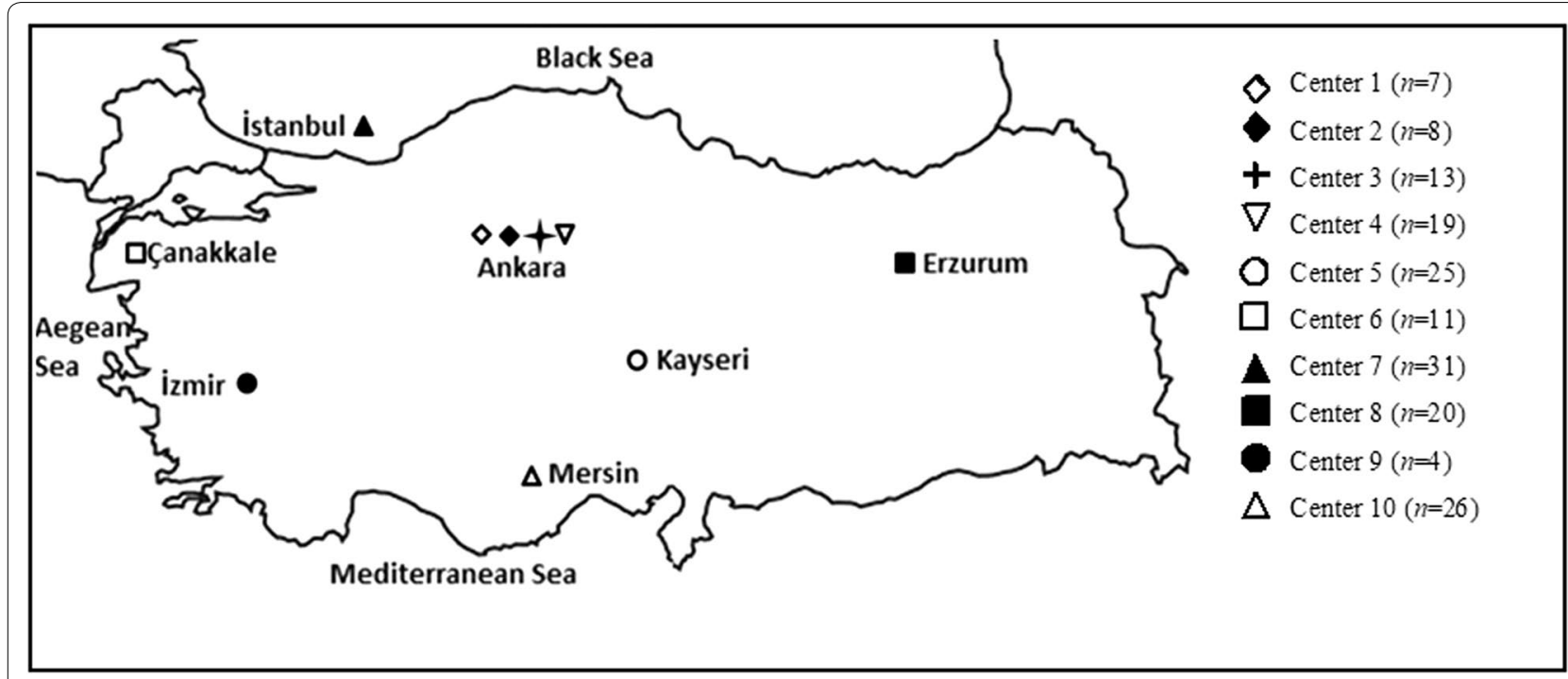

Fig. 1 Distribution of centers collaborating in the study 


\section{Pulsed-field gel electrophoresis}

PFGE of 172 isolates was implemented as previously described by Durmaz et al. [15]. Briefly, the genomic DNA was digested with ApaI (New England Biolabs, Beverly, MA). The plugs were embedded into $1 \%$ agarose gel wells. Subsequently, the separation of the DNA bands was carried out using the CHEF DR III system (Bio-Rad, Nazareth, Belgium) at $6 \mathrm{~V} / \mathrm{cm}^{2}$ for $19 \mathrm{~h}$ and the pulse time was changed from 5 to $20 \mathrm{~s}$. PFGE pattern analysis was carried out by using Bionumerics software version 4.0 (Applied Maths, Austin, TX) and with the unweighted-pair group method using average linkages. In order to analyze clusters Dice settings were used.

\section{Statistical analysis}

Univariate conditional logistic regressions were used in the study group. Odds ratios were estimated by exponentiation of regression coefficients and their 95\% confidence interval (CIs) reported. To adjust for confounding factors, variables with a $p$ value below the $10 \%$ significance level in univariate analysis were entered in multiple conditional logistic regression models.

\section{Results}

\section{Patient characteristics and risk factors}

A total of 164 patients were included in the study. Of these patients, 88 (53.6\%) were men and the age range was 15 days -78 years. The mean age of the patients was 60.1. Data from all 164 patients indicated that $52.4 \%$ of them were hospitalized in surgical ICUs, $30.5 \%$ in medical ICUs, $11 \%$ in burns units and $6.1 \%$ in emergency medicine service (Table 1). At least one underlying disease was identified in $95 \%$ of the patients. The most frequent diagnosis was ventilator-associated pneumonia (VAP) (26.6\%) followed by malignancy (23\%). The underlying diseases of patients were recorded as diabetus mellitus (DM), chronic kidney failure (CKF), chronic obstructive pulmonary disease (COPD), acute respiratory distress syndrome (ARDS), chronic liver failure (CLF) and febrile neutropenia (FEN). The risk factors for mortality contained DM [hazard ratio (HR): 2.74; $p=0.026$ ], CLF (HR: $4.27 ; p=0.047$ ), chemotherapy (HR: $3.69 ; p=0.03$ ) and previous usage of fluoroquinolones (HR: $3.64 ; p=0.01$ ) (Table 2). According to available data, carbapenems $(67 / 153)$ and third generation cephalosporins (51/153) were the most common antibiotics received by patients before the diagnosis of MDR A. baumannii infection.

\section{Antimicrobial susceptibility testing}

The antimicrobial susceptibility test results of the 160 clinical and 12 environmental $A$. baumannii isolates were shown in Table 3. Four clinical isolates could not be regenerated during the study. A high proportion of the
Table 1 The demographic features of the patients and risk factors $(n=164)$

\begin{tabular}{lll}
\hline & Number ( $\boldsymbol{n})$ & Frequency (\%) \\
\hline Gender & 88 & 53.6 \\
Male & 76 & 46.3 \\
Female & & \\
Service & 50 & 30.5 \\
Medical ICUs & 86 & 52.4 \\
Surgical ICUs & 18 & 11 \\
Burn ICUs & 10 & 6.1 \\
Emergency service & & \\
Immunosuppression & 18 & 11 \\
Corticosteroid usage & - & - \\
Transplantation (solid organ, & & \\
$\quad$ bone marrow) & 15 & 9.1 \\
Chemotherapy & & \\
Invasive procedures & 125 & 76.2 \\
Central catheterisation & 161 & 98.2 \\
Urinary catheterisation & 112 & 68.7 \\
Mechanical ventilation & 86 & 52.4 \\
Nasogastric tube & 74 & 45.4 \\
Orotracheal intubation & 32 & 19.5 \\
Other & 96 & 58.5 \\
Mortality & &
\end{tabular}

ICU intensive care unit

isolates were resistant to AN (91.8\%), SAM (99.4\%), CAZ (99.4\%), CIP (100\%) and IMP (99.4\%) while most isolates were susceptible to COL (98.8\%) and TIG (98.3\%). Strains were considered as multidrug-resistant when the resistance was detected for at least one agent in three or more different categories of antimicrobials according to the definition of Magiorakos et al. [16].

\section{Detection of antibiotic resistance genes}

All A. baumannii isolates possessed bla $a_{\mathrm{OXA}-51}$ gene. The $b l a_{\text {OXA-23 }}$ gene was detected in $166 / 172(96 \%)$ isolates while $b l a_{\text {OXA-58 }}$ was detected only in $5 / 172(3 \%)$ isolates and none of the isolates had $b l a_{\text {OXA-24 }}$ gene. One isolate carried both $b l a_{\mathrm{OXA}-23}$ and $b l a_{\mathrm{OXA}-58}$ genes. The $b l a_{\mathrm{OXA}-23}$ was detected in all centers whereas $b l a_{\text {OXA-58 }}$ gene was detected only in Center 5 . The $b l a_{\text {PER-1 }}$ gene was detected from three centers; Center $9(n=2)$, Center $10(n=2)$ and Center $7(n=1)$. None of the isolates showed $b l a_{\mathrm{IMP}}$, $b l a_{\mathrm{KPC}}, b l a_{\mathrm{NDM}}$, and $b l a_{\mathrm{OXA}-48}$ genes (Fig. 2).

\section{Molecular epidemiology}

PFGE typing of the 172 isolates revealed 88 pulsotypes. Twenty-nine of these pulsotypes included two or more strains which could not be differentiated from each other. Totally 98 strains were classified in 29 pulsotypes, 
Table 2 The risk factors of mortality among patients $(n=164)$

\begin{tabular}{|c|c|c|c|c|}
\hline & \multirow{2}{*}{$\begin{array}{l}\text { Mortality } \\
(n=96)\end{array}$} & \multirow[t]{2}{*}{ Survival $(n=68)$} & \multicolumn{2}{|l|}{ Univariate analysis } \\
\hline & & & Risk ratio (\%95 Cl) & $p$ value \\
\hline \multicolumn{5}{|l|}{ Demographic features } \\
\hline Age & & & $1.863(1.251-2.775)$ & 0.001 \\
\hline$<64$ & 39 & 45 & & \\
\hline$>65$ & 57 & 23 & & \\
\hline Gender & & & $1.380(0.0939-2.028)$ & 0.093 \\
\hline Male & 48 & 43 & & \\
\hline Female & 48 & 25 & & \\
\hline \multicolumn{5}{|l|}{ Comorbidity } \\
\hline Diabetes mellitus & 23 & 7 & $2.746(1.103-6.833)$ & 0.026 \\
\hline Chronic obstructive pulmonary diseases & 12 & 6 & $1.476(0.525-4.149)$ & 0.458 \\
\hline Congestive heart failure & 12 & 8 & $1.071(0.413-2.781)$ & 0.887 \\
\hline Chronic liver failure & 11 & 2 & 4.271 (0.915-19.932) & 0.047 \\
\hline Corticosteroid usage & 8 & 11 & $0.471(0.179-1.242)$ & 0.122 \\
\hline Neutropenia & 4 & 2 & $1.435(0.255-8.065)$ & 0.680 \\
\hline Malignancy & 27 & 12 & $1.826(0.849-3.924)$ & 0.120 \\
\hline Chemotherapy & 14 & 3 & $3.699(1.020-13.421)$ & 0.035 \\
\hline \multicolumn{5}{|l|}{ Invasive procedures } \\
\hline Mechanical ventilation & 67 & 38 & $1.824(0.955-3.484)$ & 0.067 \\
\hline Central catheterisation & 74 & 54 & $0.872(0.409-1.858)$ & 0.723 \\
\hline Urinary catheterisation & 94 & 66 & $1.424(0.196-10.368)$ & 0.726 \\
\hline \multicolumn{5}{|l|}{ Drugs used before diagnosis } \\
\hline Penicillin and derivatives & 29 & 15 & $1.529(0.744-3.142)$ & 0.246 \\
\hline 3rd generation cephalosporins & 32 & 23 & $1.067(0.542-2.099)$ & 0.852 \\
\hline Fluoroquinolones & 22 & 5 & $3.646(1.30-10.227)$ & 0.010 \\
\hline Aminoglycosides & 7 & 2 & $2.512(0.504-12.510)$ & 0.246 \\
\hline Carbapenems & 49 & 37 & $0.840(0.438-1.610)$ & 0.599 \\
\hline Colistin & 3 & 5 & $0.391(0.090-1.699)$ & 0.196 \\
\hline
\end{tabular}

The value of $p<0.05$ was set as the significance threshold (in italics)

$\mathrm{Cl}$ confidence interval

Table 3 Antimicrobial susceptibility of invasive MDR A. baumannii isolates from ICUs $(n=172)$

\begin{tabular}{lllll}
\hline Antimicrobial agent & $\mathbf{M I C}_{\mathbf{5 0}}(\mathbf{m g} / \mathbf{L})$ & MIC $_{\mathbf{9 0}}(\mathbf{m g} / \mathbf{L})$ & MIC range $(\mathbf{m g} / \mathbf{L})$ & Resistance $(\%)$ \\
\hline Amikacin & $\geq 256$ & $\geq 256$ & 1 to $\geq 256$ & 91.8 \\
Ampicillin-sulbactam & 256 & $\geq 256$ & 32 to $\geq 256$ & 99.4 \\
Ceftazidime & 256 & $\geq 256$ & 16 to $\geq 256$ & 99.4 \\
Ciprofloxacin & 128 & $\geq 256$ & 8 to $\geq 256$ & 100 \\
Imipenem & 64 & 128 & 1 to $\geq 256$ & 99.4 \\
Colistin & 0.5 & 1.0 & $0.25-64$ & 1.2 \\
Tigecycline & 1.0 & 2.0 & $0.01-3$ & 1.7 \\
\hline
\end{tabular}

the clustering rate was $57 \%$. When the similarity rate between the pulsotypes was assigned as $\geq 85 \%, 157$ clonally related strains (91.2\%) were clustered in 14 PFGE groups (I-XIV). Group VI $(n=27)$ was the largest among the PFGE groups followed by the groups II $(n=24)$ and
IX $(n=21)$. Since dendrogram of all pulsotypes was very large, a cross-sectional example of dendrogram representing the most common PFGE group was shown as Fig. 3. Evaluation of the PFGE group types according to the centers revealed that group VI was dominant in three 


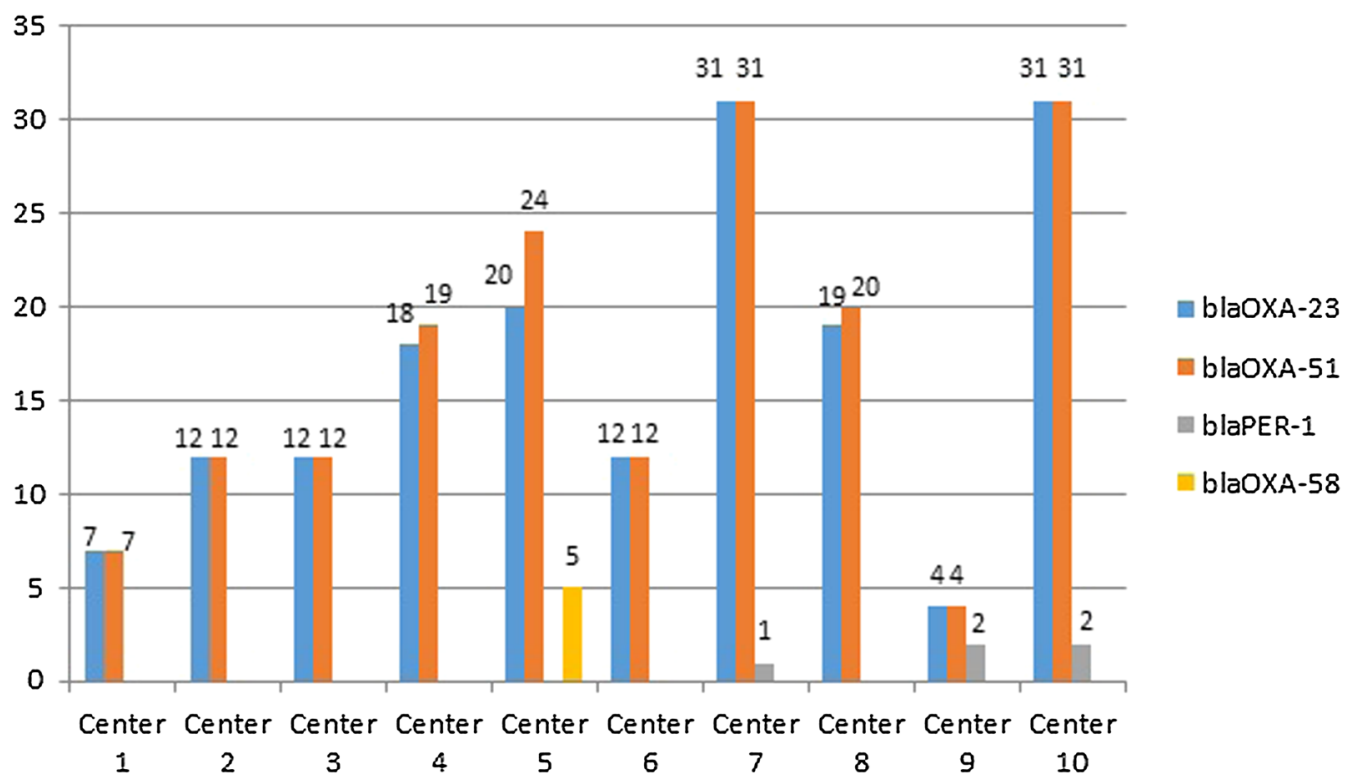

Fig. 2 The frequency of resistance genes according to centers

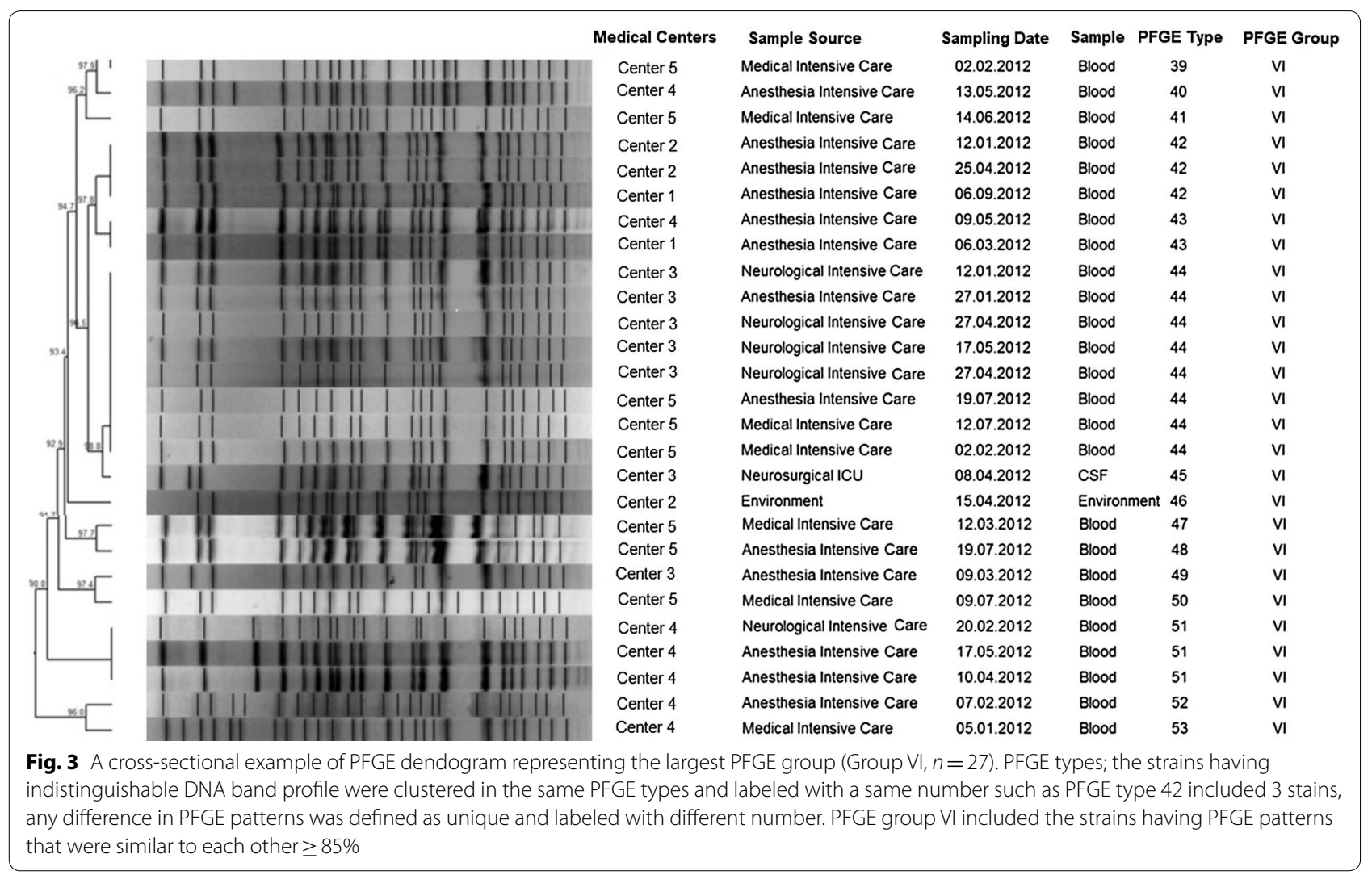

centers (Center 3, Center 4, and Center 5) and was the second most dominant type in two centers (Center 1 and Center 2). The clinical $(n=10)$ and environmental $(n=2)$ isolates recovered from different ICUs of Center 6 were in the PFGE group IV and these isolates were all identical. In five centers located in Central Anatolia, group VI 
was the dominant group. Group II was detected more often in two centers (Center 9 and Center 10). In group XII, isolates were only from Center 7, and 11 of these isolates were obtained from the burns unit. Center 8 differed from the other centers since the dominant group type was XIV for this center.

\section{Discussion}

Acinetobacter baumannii has become one of the most serious threats especially in the ICUs of the hospitals being respondless to antibiotic therapy. Therefore, new strategies should be adopted to combat this pathogen. At this point, data obtained from especially multicenter studies is needed to understand the epidemiology of $A$. baumannii. The examination of demographic characteristics of patients with MDR A. baumannii infections, detection of resistance genes and the spread of resistant strains in hospitals can help to control these infection. In this study, epidemiological characteristics of invasive A. baumannii strains from 10 medical centers in five different geographical regions of Turkey were evaluated. To our knowledge, the current study is the most comprehensive epidemiological study in Turkey in terms of distribution and number of participant centers and isolates.

The important risk factors for mortality in patients with $A$. baumannii infections were long-term medication in ICUs, APACHE II score > 20, ventilator associated bacteremia, use of third generation cephalosporins before the diagnosis of infection and liver cirrhosis [17]. In our study, being $>65$ age, having DM or CLF, taking chemotherapeutic drugs or fluoroquinolones before diagnosis were found to be related with mortality. On the contrary, using carbapenem or third generation cephalosporins was not found to be related to mortality in the studied patient population.

According to surveillance studies, carbapenem resistance is a major problem in the treatment of A. baumannii infections especially in Turkey, Greece, Italy, Spain, Romania and the UK $[2,18]$. In our study, colistin was the most effective antimicrobial agent against MDR A. baumannii isolates, confirming the multicenter study which SENTRY performed between 2001 and 2011 and it was reported that colistin had low level resistance (0.9-3.3\%) and was still effective against MDR A. baumannii isolates [19].

Among the resistance genes responsible for carbapenem resistance in $A$. baumannii isolates, $b l a_{\text {OXA-23, }}$, $b l a_{\text {OXA-24 }}$ and $b l a_{\text {OXA- } 58}$ are the top leading ones. The dominance of these genes in resistant A. baumannii isolates has been changed all over the world. The predominance of bla OXA-58 $_{\text {between }} 1999$ and 2009 in Mediterranean countries like Italy, Greece, Lebanon and Turkey has showed a transition to bla $a_{\text {OXA-23 }}$ since 2009 causing an increase in the frequency of $b l a_{\text {OXA-23. }}$. This rise caused of a higher carbapenem $\mathrm{MIC}_{50}$ and $\mathrm{MIC}_{90}$ values between $2010(16 \mathrm{mg} / \mathrm{L}$ and $256 \mathrm{mg} / \mathrm{L}$, respectively) and $2011(128 \mathrm{mg} / \mathrm{L}$ and $256 \mathrm{mg} / \mathrm{L})$ [20]. There are some reports about the rise of $b l a_{\text {OXA-23 }}$ gene in carbapenem resistant strains of A. baumannii in Turkey [21, $22]$. Although the study populations and duration time of these studies had some differences, there was a consensus about the increasing number of MDR A. baumannii isolates which have $b l a_{\mathrm{OXA}-23}$ gene. As the $b l a_{\mathrm{OXA}-23}$ enzyme was found in all centers but $b l a_{\text {OXA-58 }}$ only in one center, the results of the current study highlighted that $b l a_{\text {OXA-23 }}$ gene is the most prevalent oxacillinase in Turkey.

The frequency of $b l a_{\text {PER-1 }}$ can vary from country to country. In Turkey according to the local studies, the frequency of bla $a_{\text {PER-1 }}$ among MDR A. baumannii isolates has been in a declining trend (52.9\% to $8.3 \%)$ since 2008 . In our study, the frequency of $b l a_{\mathrm{PER}-1}$ was found to be $2.8 \%$. According to previous reports, the annual rate of PER-1 detection decreased gradually over time and the most prominent decrease occurred in 2010 in Turkey. The frequency of PER- 1 type $\beta$-lactamases in A. baumannii species has decreased, and PER-1 is no longer a threat in Turkey's resistance profile [23].

The important feature in the surveillance of MDR $A$. baumannii isolated from patients with hospital infections is the typing of strains by using a standard method such as PFGE. The use of PFGE especially in multicenter studies is very important to estimate the clonal relatedness between isolates obtained from different centers. A previous study revealed that $60-80 \%$ of the strains were clonally related throughout the country [24]. In the current study, the PFGE results of the clinical and environmental MDR A. baumannii strains isolated from the ICUs of Center 6, Center 7 and Center 10 revealed the same pulsotype although the regions of these centers are far away from each other. Furthermore, one of the clinical isolates of Center 10 was identical to the environmental isolate of Center 2, which is quite interesting since the regions are also far away from each other.

Some of the strains which were responsible for mini epidemics in ICUs of different centers showed the same pulsotype profile with $91.2 \%$ relatedness and this result revealed that these isolates did not differ so much from each other. Detection of the same or very similar pulsotypes from different centers suggests that infection control measures should be strengthened and revised in our country. This situation can be achieved with the measures indicated in the report of Cheon et al. which described the control of endemic MDR A. baumannii outbreaks in ICUs within 1 year with comprehensive and intensive infection control measures such as effective antibiotic management, personnel training, contact precautions, 
hand hygiene and active surveillance cultures of hospital environmental samples [25].

The current study also has some limitations. Although ten centers from five different regions of Turkey were included in the study, further studies with the participation of more centers are needed. Moreover, the mortality rates in the current study might be different to those in other comprehensive studies since almost all patients were immunosuppressive and had underlying diseases.

In conclusion, the results of this study indicates that clinical and environmental A. baumannii isolates obtained from different centers in Turkey are closely related to each other, the resistance against carbapenems is by far the most important emergency for $A$. baumannii infections and $b l a_{\mathrm{OXA}-23}$ has become the most prevalent carbapenemase in Turkey.

\section{Acknowledgements}

The Acinetobacter Study Group members: Pinar Zarakolu, Hacettepe University, Faculty of Medicine, Department of Infectious Diseases and Clinical Microbiology, Ankara, Turkey; Gülden Ersöz, Mersin University Faculty of Medicine, Department of Infectious Diseases and Clinical Microbiology, Mersin, Turkey; Ali Kaya, Mersin University Faculty of Medicine, Department of Infectious Diseases and Clinical Microbiology, Mersin, Turkey; Demet Haciseyitoglu, University of Health Sciences Dr Lutfi Kirdar Education and Research Hospital Department of Medical Microbiology, Istanbul, Turkey; Öznur Ak, University of Health Sciences Dr Lutfi Kirdar Education and Research Hospital, Department Infectious Diseases and Clinical Microbiology, Istanbul, Turkey; Serap Gencer, University of Health Sciences Dr Lutfi Kirdar Education and Research Hospital, Department Infectious Diseases and Clinical Microbiology, Istanbul, Turkey; Acibadem Mehmet Ali Aydinlar University Faculty of Medicine, Department of Infectious Diseases and Clinical Microbiology, Istanbul, Turkey; Fatma Mutlu Sarigüzel, Erciyes Üniversity Faculty of Medicine, Department of Medical Microbiology, Kayseri, Turkey; Illhami Çelik, Kayseri Education and Research Hospital, Department of Infectious Diseases and Clinical Microbiology, Kayseri, Turkey; Muhammet Hamdullah Uyanik, Atatürk University, Faculty of Medicine, Department of Medical Microbiology, Erzurum, Turkey; Kemalettin Özden, Atatürk University, Faculty of Medicine, Department of Infectious Diseases and Clinical Microbiology, Erzurum, Turkey; Ziya Cibali Acikgöz, Ankara Yildirim Beyazit University Faculty of Medicine, Department of Medical Microbiology, Ankara, Turkey; Rahmet Guner, Ankara Yildirim Beyazit University Faculty of Medicine, Department of Infectious Diseases and Clinical Microbiology, Ankara, Turkey; Alper Akcali, Canakkale Onsekiz Mart University, Faculty of Medicine, Department of Medical Microbiology, Canakkale, Turkey; Alper Sener, Canakkale Onsekiz Mart University, Faculty of Medicine, Department of Infectious Diseases and Clinical Microbiology, Canakkale, Turkey; Ali Adiloglu, Ankara Education and Research Hospital, Department of Medical Microbiology, Ankara, Turkey; Cemal Bulut, Ankara Education and Research Hospital, Department of Infectious Diseases and Clinical Microbiology, Ankara, Turkey; Kirikkale University Faculty of Medicine Department of Infectious Diseases and Clinical Microbiology, Kirikkale, Turkey; Meltem Yalinay, Gazi University, Faculty of Medicine, Department of Medical Microbiology, Ankara, Turkey; Murat Dizbay, Gazi University, Faculty of Medicine, Department of Infectious Diseases and Clinical Microbiology, Ankara, Turkey; Söhret Aydemir, Ege University, Faculty of Medicine, Department of Medical Microbiology, Izmir, Turkey; Oguz Resat Sipahi, Ege University, Faculty of Medicine, Department of Infectious Diseases and Clinical Microbiology, Izmir, Turkey.

\section{Authors' contributions}

$B B$, and ÖKE designed the project. Acinetobacter Study Group provided the isolates and all hospital data about patients and isolates. BB, ÖKE, ÖU, and RD performed the laboratory experiments. $B B, A E$, and ÖKE analyzed the data. $B B$, $A E$, and ÖKE wrote the paper with input from all authors. ÖKE supervised and coordinated the project. All authors read and approved the final manuscript.

\section{Funding}

This study was supported by a Hacettepe University Scientific Research Unit (Project no: 011 D07 101 007-135) grant.

\section{Availability of data and materials}

Not applicable.

\section{Ethics and approval and consent to participate}

The Ethics Committee of Hacettepe University approved the study.

\section{Consent for publication}

Not applicable.

\section{Competing interests}

The authors declare that they have no competing interests.

\section{Author details}

${ }^{1}$ Department of Medical Microbiology, Hacettepe University Faculty of Medicine, Ankara, Turkey. ${ }^{2}$ Department of Microbiology Reference Laboratories, National Molecular Microbiology Reference Laboratory, Ankara, Turkey.

${ }^{3}$ Hacettepe University School of Health Services, Ankara, Turkey. ${ }^{4}$ Department of Medical Microbiology, Ankara Yildirim Beyazit University Faculty of Medicine, Ankara, Turkey.

Received: 13 October 2018 Accepted: 21 June 2019

Published online: 02 July 2019

\section{References}

1. World Health Organisation. Antimicrobial resistance: global report on surveillance. 2014.

2. Peleg AY, Seifert H, Paterson DL. Acinetobacter baumannii: emergence of a successful pathogen. Clin Microbiol Rev. 2008;21(3):538-82.

3. McConnell MJ, Actis L, Pachon J. Acinetobacter baumannii: human infections, factors contributing to pathogenesis and animal models. FEMS Microbiol Rev. 2013;37(2):130-55.

4. Papadimitriou-Olivgeris M, Fligou F, Spiliopoulou A, Koutsileou K, Kolonitsiou F, Spyropoulou A, Zotou A, Marangos M, Anastassiou ED, Christofidou M, Spiliopoulou I. Risk factors and predictors of carbapenemresistant Pseudomonas aeruginosa and Acinetobacter baumannii mortality in critically ill bacteraemic patients over a 6-year period (2010-15): antibiotics do matter. J Med Microbiol. 2017;66:1092-101.

5. Russotto V, Cortegiani A, Graziano G, Saporito L, Raineri SM, Mammina C, Giarratano A. Bloodstream infections in intensive care unit patients: distribution and antibiotic resistance of bacteria. Infect Drug Resist. 2015;8:287-96.

6. Poirel L, Nordmann P. Carbapenem resistance in Acinetobacter baumannii: mechanisms and epidemiology. Clin Microbiol Infect. 2006;12(9):826-36.

7. Wong D, Nielsen TB, Bonomo RA, Pantapalangkoor P, Luna B, Spellberg B. Clinical and pathophysiological overview of Acinetobacter infections: a century of challenges. Clin Microbiol Rev. 2017;30(1):409-47.

8. Nigro SJ, Hall RM. Structure and context of Acinetobacter transposons carrying the oxa23 carbapenemase gene. J Antimicrob Chemother. 2016:71(5):1135-47.

9. Mohajeri P, Farahani A, Feizabadi MM, Norozi B. Clonal evolution multidrug resistant Acinetobacter baumannii by pulsed-field gel electrophoresis. Indian J Med Microbiol. 2015;33(1):87-91.

10. Clinical and Laboratory Standards Institute (CLSI). Performance standards for antimicrobial susceptibility testing; Twenty-fourth informational supplement. CLSI document M100-S24. Wayne: CLSI; 2014.

11. Pfizer Inc. (Wyeth Pharmaceuticals): Tygaci ${ }^{\circledR}$ Product Insert. Pfizer. 2013. http://www.pfizerpro.com. Accessed 21 May 2017.

12. Woodford N, Ellington MJ, Coelho JM, Turton JF, Ward ME, Brown S, Amyes SG, Livermore D. Multiplex PCR for genes encoding prevalent OXA carbapenemases in Acinetobacter spp. Int J Antimicrob Agents. 2006;27(4):351-3.

13. Poirel L, Walsh TR, Cuvillier V, Nordmann P. Multiplex PCR for detection of acquired carbapenemase genes. Diagn Microbiol Infect Dis. 2011;70(1):119-23. 
14. Weldhagen GF, Poirel L, Nordmann P. Ambler class A extended-spectrum beta-lactamases in Pseudomonas aeruginosa: novel developments and clinical impact. Antimicrob Agents Chemother. 2003;47(8):2385-92.

15. Durmaz R, Otlu B, Koksal F, Hosoglu S, Ozturk R, Ersoy Y, Aktas E, Gursoy NC, Caliskan A. The optimization of a rapid pulsed-field gel electrophoresis protocol for the typing of Acinetobacter baumannii, Escherichia coli and Klebsiella spp. Jpn J Infect Dis. 2009;62(5):372-7.

16. Magiorakos AP, Srinivasan A, Carey RB, Carmeli Y, Falagas ME, Giske CG, Harbarth S, Hindler JF, Kahlmeter G, Olsson-Liljequist B, Paterson DL, Rice LB, Stelling J, Struelens MJ, Vatopoulos A, Weber JT, Monnet DL. Multidrug-resistant, extensively drug-resistant and pandrug-resistant bacteria: an international expert proposal for interim standard definitions for acquired resistance. Clin Microbiol Infect. 2012;18(3):268-81.

17. Liu CP, Shih SC, Wang NY, Wu AY, Sun FJ, Chow SF, Chen TL, Yan TR. Risk factors of mortality in patients with carbapenem-resistant Acinetobacter baumannii bacteremia. J Microbiol Immunol Infect. 2016;49(6):934-40.

18. Muntean D, Licker M, Horhat F, Dumitrașcu V, Săndesc D, Bedreag O, Dugăeșescu D, Coșniță DA, Krasta A, Bădițoiu L. Extensively drugresistant Acinetobacter baumannii and Proteeae association in a Romanian intensive care unit: risk factors for acquisition. Infect Drug Resist. 2018;8(11):2187-97.

19. Cai Y, Chai D, Wang R, Liang B, Bai N. Colistin resistance of Acinetobacter baumannii: clinical reports, mechanisms and antimicrobial strategies. J Antimicrob Chemother. 2012;67(7):1607-15.

20. Liakopoulos A, Miriagou V, Katsifas EA, Karagouni AD, Daikos GL, Tzouvelekis LS, Petinaki E. Identification of Oxa-23 producing Acinetobacter baumannii in Greece, 2010-2011. Euro Surveill. 2012:17(11):20117.
21. Cicek AC, Saral A, Iraz M, Ceylan A, Duzgun AO, Peleg AY, Sandalli C. Oxa and GES-type beta-lactamases predominate in extensively drug resistant Acinetobacter baumannii isolates from a Turkish University Hospital. Clin Microbiol Infect. 2014;20(5):410-5.

22. Ergin A, Hascelik G, Eser OK. Molecular characterization of oxacillinases and genotyping of invasive Acinetobacter baumannii isolates using repetetive extragenic palindromic sequence-based polymerase chain reaction in Ankara between 2004 and 2010. Scand J Infect Dis. 2013:45(1):26-31.

23. Asik G, Ozdemir M, Kurtoglu MG, Yagci S, Oksuz L, Gul M, Kocoglu ME, Sesli Cetin E, Seyrek A, Berktas M, Ayyildiz A, Ciftci AH. Detection of the frequency of PER-1 type extended-spectrum beta-lactamase producing Acinetobacter baumannii clinical isolates in Turkey: a multicenter study. Turk J Med Sci. 2014;44(6):1041-6.

24. Cetin S, Durmaz R, Tetik T, Otlu B, Kaya S, Çalişkan A. Epidemiologic characterization of nosocomial Acinetobacter baumannii infections in a Turkish University hospital by pulsed-field gel electrophoresis. Am J Infect Control. 2009;37(1):56-64.

25. Cheon S, Kim MJ, Yun SJ, Moon JY, Kim YS. Controlling endemic multidrug-resistant Acinetobacter baumannii in Intensive Care Units using antimicrobial stewardship and infection control. Korean J Intern Med. 2016;31(2):367-74

\section{Publisher's Note}

Springer Nature remains neutral with regard to jurisdictional claims in published maps and institutional affiliations.
Ready to submit your research? Choose BMC and benefit from:

- fast, convenient online submission

- thorough peer review by experienced researchers in your field

- rapid publication on acceptance

- support for research data, including large and complex data types

- gold Open Access which fosters wider collaboration and increased citations

- maximum visibility for your research: over $100 \mathrm{M}$ website views per year

At BMC, research is always in progress.

Learn more biomedcentral.com/submissions 